\title{
Removal of a migrated biliary stent perforating the colonic wall: a case description of endoscopic repair
}

Endoscopically placed biliary stents are commonly used for the treatment of pancreaticobiliary disorders. Plastic biliary stent migration is a complication that occurs in $6 \%-7.5 \%$ of cases [1]. Perforation of the gastrointestinal tract secondary to stent migration is a rare event, occurring in less than $1 \%$ of cases. Reported cases of this complication have required surgery for stent removal and repair. This is a case report of a migrated biliary stent causing a perforation that was managed endoscopically.

A 90-year-old woman with recurrent biliary obstruction secondary to gallstones and Mirizzi's syndrome was being managed with sequential biliary stent exchanges. The patient presented to hospital with a sudden onset of severe abdominal pain, fevers, and rigors. On physical examination, her abdomen was tender in the right upper quadrant. An abdominal computed tomography (CT) scan identified a migrated biliary stent in the ascending colon, one end of which was perforating the colonic wall, with evidence of surrounding fat stranding but no intraperitoneal free air ( $\triangleright$ Fig. $\mathbf{1}$ ).

The patient was admitted for treatment with intravenous antibiotics and observation. In view of the patient's multiple comorbidities and her own preference, an attempt at endoscopic management was undertaken, with surgical management reserved in case of failure. The stent was successfully removed, and the defect was repaired with endoscopic clips and an endoloop ( $\triangleright$ Video 1 ; $>$ Fig. 2 ). The patient did well and was subsequently sent home on a course of oral antibiotics.

The efficacy of repair for perforations using hemostatic clips is limited by the clip size, and the amount of pressure each clip can apply across a defect [2]. As such, using an endoloop around the clips reinforces and further stabilizes the closure. The technique is analogous to a purse-string suture. This case and ac-
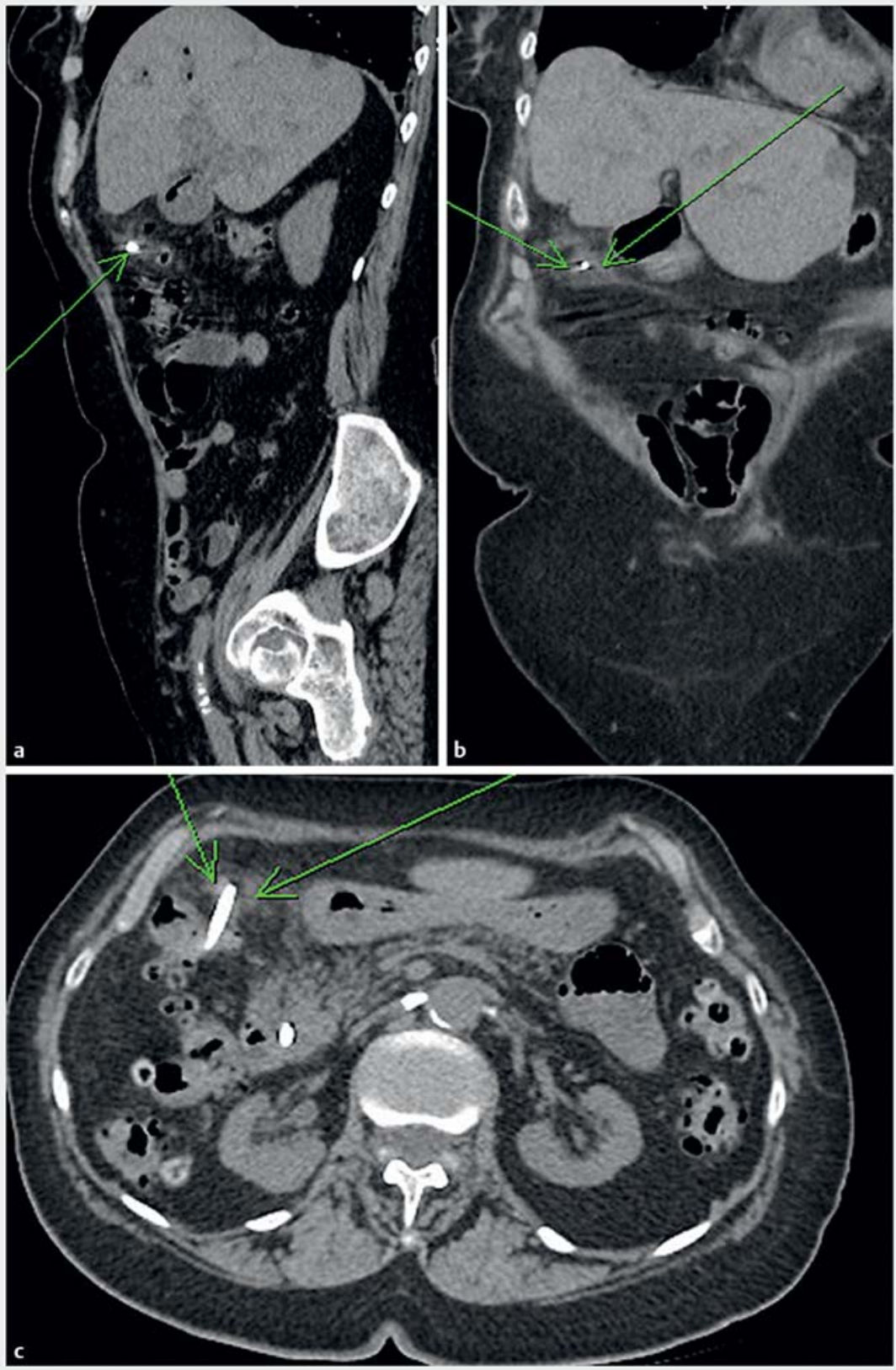

Fig. 1 Computed tomography (CT) scan images showing a biliary stent passing through the colonic wall in the ascending colon in: a sagittal; b coronal; and $\mathbf{c}$ axial view.

companying video illustrate the benefits Endoscopy_UCTN_Code_CPL_1AK_2AI 


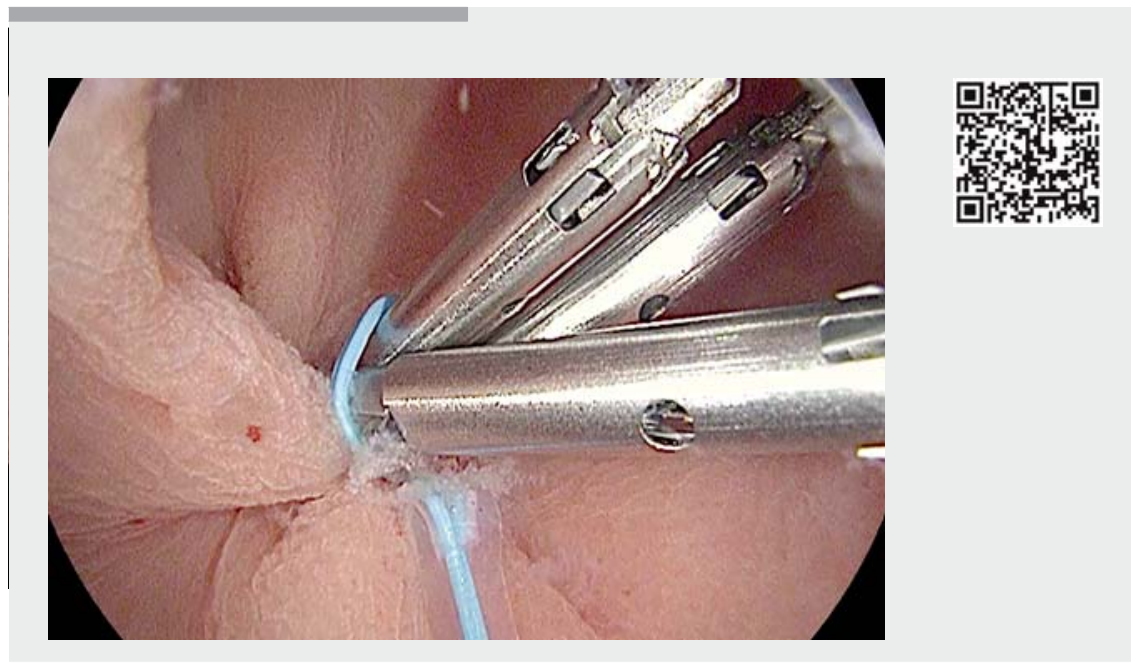

$\checkmark$ Video 1 The stent was removed from the wall of the ascending colon using a snare. The defect was closed with three clips, and an endoloop to approximate the mucosa.

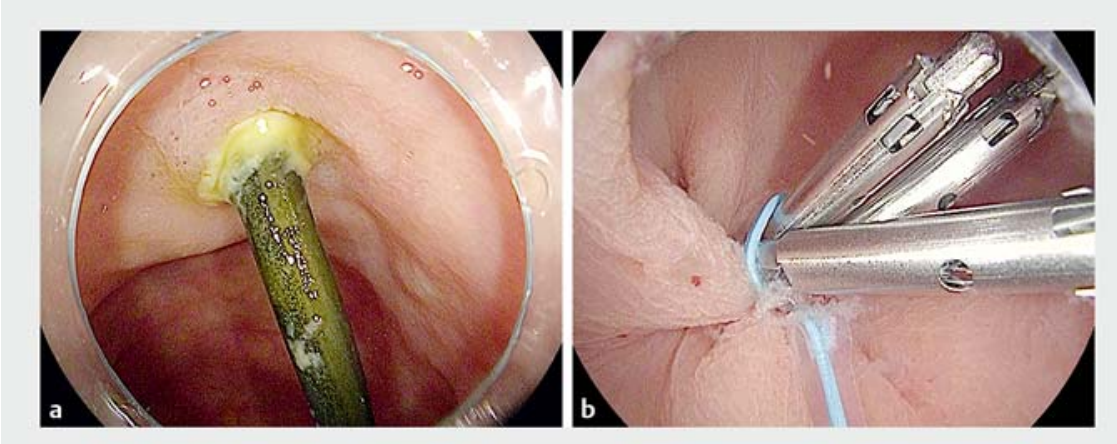

- Fig. 2 Endoscopic views showing: a the impacted biliary stent passing through the colonic wall; $\mathbf{b}$ the colonic perforation after closure using three hemostatic clips and an endoloop.

The authors

None

Konstantinos Hnaris, Robert Bechara

Kingston Health Sciences Center, Division of Gastroenterology, Kingston, Ontario, Canada
Corresponding author

\section{Konstantinos Hnaris, MDCM}

Kingston Health Science Center -

Gastroenterology Division, Hotel Dieu

Hospital Site, 166 Brock Street, Kingston,

Ontario, K7L 5G2, Canada

17kh6@queensu.ca

\section{References}

[1] Johansen JF, Shmalz M], Geenen JE. Incidence and risk factors for biliary and pancreatic stent migration. Gastrointest Endosc 1992; 38: $341-346$

[2] Rustagi T, McCarty TR, Aslanian HR. Endoscopic treatment of gastrointestinal perforations, leaks, and fistulae. J Clin Gastroenterol 2015; 49: 804-809

\section{Bibliography}

DOI https://doi.org/10.1055/a-0889-7085

Published online: 16.5.2019

Endoscopy 2019; 51: E282-E283

(c) Georg Thieme Verlag KG

Stuttgart · New York

ISSN 0013-726X

\section{ENDOSCOPY E-VIDEOS}

https://eref.thieme.de/e-videos

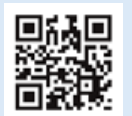

Endoscopy E-Videos is a free access online section, reporting on interesting cases and new

techniques in gastroenterological endoscopy. All papers include a high quality video and all contributions are freely accessible online.

This section has its own submission website at https://mc.manuscriptcentral.com/e-videos 